\title{
Validation of a new transpulmonary thermodilution system to assess global end- diastolic volume and extravascular lung water
}

\author{
Karim Bendjelid ${ }^{1 *}$, Raphael Giraud ${ }^{1}$, Nils Siegenthaler ${ }^{1}$, Frederic Michard ${ }^{2}$
}

\begin{abstract}
Introduction: A new system has been developed to assess global end-diastolic volume (GEDV), a volumetric marker of cardiac preload, and extravascular lung water (EVLW) from a transpulmonary thermodilution curve. Our goal was to compare this new system with the system currently in clinical use.

Methods: Eleven anesthetized and mechanically ventilated pigs were instrumented with a central venous catheter and a right (PulsioCath; Pulsion, Munich, Germany) and a left (VolumeView ${ }^{\mathrm{TM}}$; Edwards Lifesciences, Irvine, CA, USA) thermistor-tipped femoral arterial catheter. The right femoral catheter was used to measure GEDV and EVLW using the $\mathrm{PiCCO}_{2}{ }^{\mathrm{TM}}$ (Pulsion) method (GEDV 1 and EVLW ${ }_{1}$, respectively). The left femoral catheter was used to measure the same parameters using the new VolumeView ${ }^{\mathrm{TM}}$ (Edwards Lifesciences) method (GEDV 2 and EVLW 2 , respectively). Measurements were made during inotropic stimulation (dobutamine), during hypovolemia (bleeding), during hypervolemia (fluid overload), and after inducing acute lung injury (intravenous oleic acid).
\end{abstract}

Results: One hundred and thirty-seven paired measurements were analyzed. GEDV 1 and GEDV 2 ranged from 701 to $1,629 \mathrm{ml}$ and from 774 to $1,645 \mathrm{ml}$, respectively. GEDV 1 and GEDV 2 were closely correlated $\left(r^{2}=0.79\right.$ ), with mean bias of $-11 \pm 80 \mathrm{ml}$ and percentage error of $14 \%$. EVLW 1 and EVLW2 ranged from 507 to $2,379 \mathrm{ml}$ and from 495 to $2,222 \mathrm{ml}$, respectively. EVLW 1 and EVLW 2 were closely correlated $\left(r^{2}=0.97\right)$, with mean bias of $-5 \pm 72 \mathrm{ml}$ and percentage error of $15 \%$.

Conclusions: In animals, and over a very wide range of values, a good agreement was found between the new VolumeView $^{\text {TM }}$ system and the PiCCO ${ }^{\text {TM }}$ system to assess GEDV and EVLW.

\section{Introduction}

Transpulmonary thermodilution (TPTD) is increasingly used for hemodynamic evaluations in critically ill patients [1-4]. After injection of a cold indicator in the superior vena cava, TPTD allows the computation of cardiac output $(\mathrm{CO})$ from a TPTD curve recorded by a thermistor-tipped femoral arterial catheter [4]. Additional physiological parameters can be derived from the dilution curve, such as global end diastolic volume (GEDV), a volumetric marker of cardiac preload [5-7], and extravascular lung water (EVLW) [7-10].

\footnotetext{
* Correspondence: karim.bendjelid@hcuge.ch

'Department of APSI, Geneva University Hospitals, 4 rue Gabrielle-PerretGentil, Genève 14-1211, Switzerland

Full list of author information is available at the end of the article
}

The TPTD method currently in clinical use and implemented in the $\mathrm{PiCCO}^{\mathrm{TM}}$ system (Pulsion Medical Systems, Munich, Germany) is based on mathematical models described in the $1950 \mathrm{~s}[11,12]$. A new and original method has recently been developed to derive GEDV and EVLW from a TPTD curve (VolumeView ${ }^{\mathrm{rm}}$; Edwards Lifesciences, Irvine, CA, USA). The aim of the present animal study was to compare the new VolumeView $^{\text {TM }}$ system with the $\mathrm{PiCCO}^{\mathrm{TM}}$ system, over a wide range up to extreme pathophysiological conditions.

\section{Materials and methods}

The study was approved for the use of swine by the Institutional Animal Care and Use Committee at the Edwards Lifesciences Biological Resource Center, and all experimentation was done in accordance with the Guide

\section{Biomed Central}


for the Care and Use of Laboratory Animals (1996; ILAR, NAP, Washington, DC, USA).

Eleven anesthetized and mechanically ventilated pigs (90 to $110 \mathrm{~kg}$ ) were studied. Animals were premedicated with intramuscular midazolam $(0.5 \mathrm{mg} / \mathrm{kg})$ and atropine $(0.5 \mathrm{mg})$ and were anesthetized with an injection of propofol $(1 \mathrm{mg} / \mathrm{kg})$ followed by continuous infusion of propofol $(150 \mu \mathrm{g} / \mathrm{kg} / \mathrm{min})$ and sufentanil $(2.5 \mu \mathrm{g} / \mathrm{kg} / \mathrm{h})$. After tracheal intubation, pigs were mechanically ventilated in a volume-controlled mode with a $\mathrm{FiO}_{2}$ of $50 \%$, a respiratory rate between 12 and 16 breaths/minute (to maintain an end-expiratory partial pressure of carbon dioxide within the normal range), a positive end-expiratory pressure of $0 \mathrm{cmH}_{2} \mathrm{O}$ and a tidal volume of $10 \mathrm{ml} /$ $\mathrm{kg}$.

All animals were instrumented with a right (PulsioCath $^{\mathrm{TM}}$; Pulsion Medical Systems) and a left (VolumeView $^{\mathrm{TM}}$; Edwards Lifesciences) $5 \mathrm{~F}$ thermistor-tipped femoral arterial catheter. The correct position of femoral catheters was confirmed by radioscopy (Figure 1).

All animals were also instrumented with a pulmonary artery catheter CCComboV $^{\mathrm{TM}}$, 7.5F; Edwards Lifesciences) inserted through the right jugular vein and with a central venous catheter in the left jugular vein (Figure 1). The pulmonary artery catheter was used for continuous monitoring of CO (Vigilance II; Edwards Lifesciences) and pulmonary arterial pressures during the experimental protocol. The central venous catheter was used for cold indicator injections and for central venous pressure monitoring. Pulmonary artery pressures, continuous $\mathrm{CO}$ and central venous pressure data were used to guide therapy at various stages (as described below) but were not recorded nor analyzed.

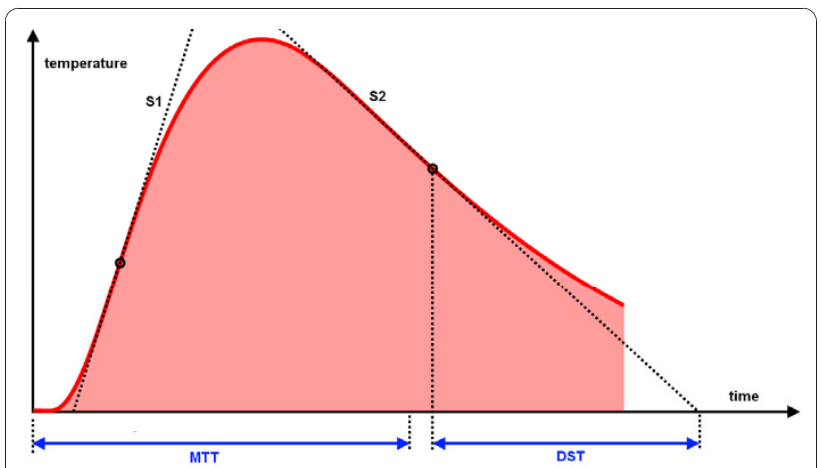

Figure 1 Transpulmonary thermodilution curve. The assessment of global end-diastolic volume (GEDV) by the PiCCO ${ }^{\mathrm{TM}}$ system is based on the mean transit time (MTt) and exponential downslope time (DSt), while the assessment of GEDV by the new

VolumeView ${ }^{\mathrm{TM}}$ method is based on MTt, maximum ascending slope (S1) and maximum descending slope (S2).

\section{The current transpulmonary thermodilution system}

The right femoral catheter was connected to a $\mathrm{PiCCO}_{2}{ }^{\mathrm{rm}}$ monitor (Pulsion Medical Systems) and used to measure $\mathrm{CO}\left(\mathrm{CO}_{1}\right)$, GEDV $\left(\mathrm{GEDV}_{1}\right)$ and EVLW $\left(\mathrm{EVLW}_{1}\right)$ using the following equations $[1,7,9,10]$ :

$$
\mathrm{CO}_{1}=V_{i}\left(T_{b}-T_{i}\right) k / \mathrm{AUC}
$$

where $V_{\mathrm{i}}$ is the injectate volume, $T_{\mathrm{b}}$ is blood temperature, $T_{\mathrm{i}}$ is injectate temperature, $k$ is a constant proportional to the specific weights and specific heat of blood and injectate, and AUC is the area under the TPTD curve.

$$
\mathrm{GEDV}_{1}=\mathrm{CO}_{1} \times(\mathrm{MTt}-\mathrm{DSt})
$$

where MTt is the mean transit time of the cold indicator and DSt is the exponential downslope time (Figure 1).

$$
\mathrm{EVLW}_{1}=\left(\mathrm{CO}_{1} \times \mathrm{MTt}\right)-\left(1.25 \times \mathrm{GEDV}_{1}\right)
$$

The new transpulmonary thermodilution system

The left femoral catheter was connected to the EV1000 ${ }^{\mathrm{TM}}$ monitor (Edwards Lifesciences) and used to measure $\mathrm{CO}\left(\mathrm{CO}_{2}\right)$, GEDV $\left(\mathrm{GEDV}_{2}\right)$ and EVLW $\left(E_{L V W}\right)$. CO was derived from the dilution curve using the same Stewart Hamilton equation:

$$
\mathrm{CO}_{2}=V_{i}\left(T_{b}-T_{i}\right) / \mathrm{AUC}
$$

GEDV, however, was derived from a different equation as follows:

$$
\mathrm{GEDV}_{2}=\mathrm{CO}_{2} \times \mathrm{MTt} \times \mathrm{f}(\mathrm{S} 2 / \mathrm{S} 1)
$$

where $\mathrm{S} 1$ and $\mathrm{S} 2$ are respectively the maximum ascending and descending slopes of the thermodilution curve (Figure 1 ) and $f$ is a proprietary function.

Finally, EVLW was assessed using the equation:

$$
\mathrm{EVLW}_{2}=\left(\mathrm{CO}_{2} \times \mathrm{DSt}\right)-\left(0.25 \times \mathrm{GEDV}_{2}\right)
$$

The same cold saline bolus injected through the central venous catheter was used to compute simultaneously the two transpulmonary curves: one with the right femoral catheter $\mathrm{PiCCO}_{2}{ }^{\mathrm{TM}}$ (Pulsion Medical Systems), the other with the left femoral catheter $\left(\mathrm{EV} 1000^{\mathrm{TM}}\right.$; Edwards Lifesciences). The average of three bolus measurements was considered for analysis and is reported in Results.

\section{Experimental protocol}

The experimental protocol is summarized in Figure 2. Measurements were performed: at baseline; during 


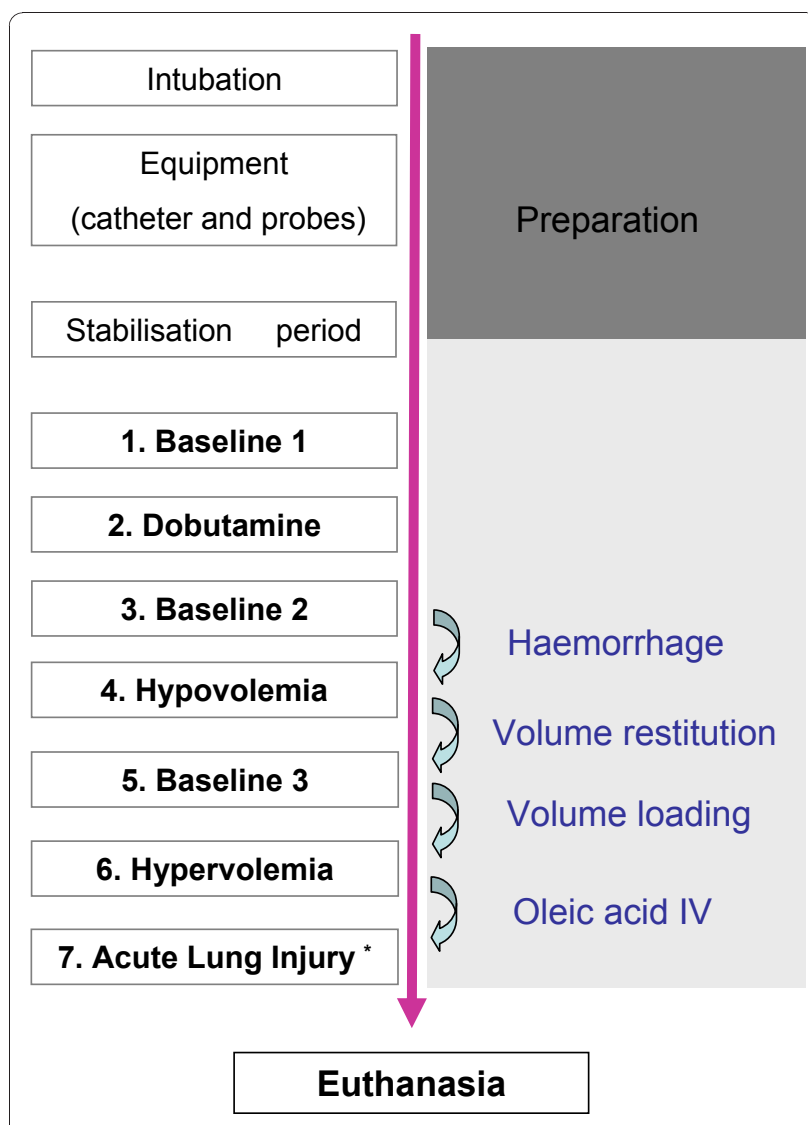

Figure 2 Flow chart of the experimental protocol. *Multiple measurements. IV, intravenous.

dobutamine infusion (DOBU, starting at $7.5 \mu \mathrm{g} / \mathrm{kg} / \mathrm{min}$ ute and titrated to induce a 30 to $50 \%$ increase in continuous $\mathrm{CO}$ ); 5 minutes after stopping dobutamine infusion; after inducing hypovolemia (HYPO, controlled hemorrhage to decrease mean arterial pressure (MAP) around $50 \mathrm{mmHg}$ ); after blood restitution and fluid loading ( $2 / 3$ blood $+1 / 3$ serum saline); and after fluid overloading (HYPER, $75 \%$ serum saline $+25 \%$ gelatin in order to increase MAP up to $130 \mathrm{mmHg}$ and/or central venous pressure up to $20 \mathrm{mmHg}$ ). At each stage, a 10-minute stabilization period was observed before doing the measurements. Finally, additional measurements were performed after inducing acute lung injury (ALI) by injecting intravenously oleic acid (O1383, $100 \mathrm{mg} / \mathrm{kg} /$ hour).

At this stage, several measurements were performed successively in order to capture high EVLW values. Oleic acid-induced pulmonary edema was confirmed by the occurrence of arterial hypoxemia (drop in $\mathrm{PaO}_{2} /$ $\mathrm{FiO}_{2}$ and $\mathrm{SaO}_{2}$ ), a drop in the compliance of the respiratory system (increase in airway pressures while the tidal volume was maintained constant or even decreased) and lung infiltrates on chest X-ray scan (Figure 1). At this point, $\mathrm{FiO}_{2}$ and the positive end-expiratory pressure were respectively increased up to $100 \%$ and $15 \mathrm{cmH}_{2} \mathrm{O}$ when necessary to maintain $\mathrm{SaO}_{2}>90 \%$. Oleic acid may induce a dramatic increase in pulmonary artery pressures and a decrease in $\mathrm{CO}$ (right ventricular failure). Phenylephrine and dobutamine were therefore also administered when necessary to maintain MAP $>50$ $\mathrm{mmHg}$ and continuous $\mathrm{CO}>5 \mathrm{l} /$ minute as long as possible. When it was no longer possible to maintain $\mathrm{SaO}_{2}$ $>90 \%$ and MAP >50 mmHg, data collection was stopped and animals were sacrificed (with pentobarbital and phenytoin).

\section{Statistical analysis}

Results are expressed as the mean \pm standard deviation (SD), unless specified otherwise. Percentage errors for CO, GEDV and EVLW comparisons were calculated as twice the SD of the bias over the average CO, GEDV or EVLW value, respectively [13]. All bias, SDs, limits of agreement (2SD) and percentage errors reported in the manuscript have been corrected for multiple measurements according to the method proposed by Bland and Altman [14].

Reproducibility of TPTD measurements was assessed by calculating the standard deviation/mean ratio of triplicate measurements and is expressed as a percentage. The effect of each intervention (DOBU, HYPO, HYPER, ALI) versus the previous stage was assessed using a parametric test (paired $t$ test) or nonparametric test (paired Wilcoxon test) when appropriate. Values obtained using both methods were also compared at each stage using unpaired tests (parametric or nonparametric as appropriate).

Several measurements were performed at the latest stage (ALI) in order to capture high EVLW values. At this stage, only measurements corresponding to the maximum $\mathrm{EVLW}_{1}$ (the reference method in the present study) have been selected for comparisons with $\mathrm{EVLW}_{2}$. For the linear regression analysis, however, all measurements were taken into account. $P<0.05$ was considered statistically significant.

\section{Results}

A total of 137 paired measurements were available for comparisons. Sixty-six paired measurements were collected from stages 1 to 6 (6 stages $\times 11$ pigs) and 71 additional paired measurements $(6.5 \pm 2.1$ per pig) were collected at the final lung injury stage. No data were discarded. The reproducibility of hemodynamic parameters is reported in Table 1.

Overall, $\mathrm{CO}_{1}$ and $\mathrm{CO}_{2}$ ranged from 3.1 to $15.4 \mathrm{l} / \mathrm{min}$ ute and from 3.4 to $15.1 \mathrm{l} /$ minute, respectively. $\mathrm{CO}_{1}$ and $\mathrm{CO}_{2}$ were closely correlated $\left(r^{2}=0.99\right)$, with mean bias $( \pm \mathrm{SD})$ of $0.20 \pm 0.30 \mathrm{l} /$ minute and percentage error of $7 \%$ (Figure 3). GEDV 1 and $\mathrm{GEDV}_{2}$ ranged from 701 to 
Table 1 Reproducibility of transpulmonary thermodilution measurements

\begin{tabular}{lll}
\hline & PiCCO $^{\text {TM }}$ method & VolumeView $^{\text {TM }}$ method \\
\hline Cardiac output (\%) & $6.3 \pm 5.1$ & $5.7 \pm 4.9$ \\
$\begin{array}{l}\text { Global end-diastolic } \\
\text { volume (\%) }\end{array}$ & $6.8 \pm 5.3$ & $6.9 \pm 5.0$ \\
$\begin{array}{l}\text { Extravascular lung } \\
\text { water (\%) }\end{array}$ & $5.5 \pm 4.0$ & $5.7 \pm 4.2$ \\
\hline
\end{tabular}

Data presented as mean \pm standard deviation.

$1,629 \mathrm{ml}$ and from 774 to $1,645 \mathrm{ml}$. GEDV 1 and $\mathrm{GEDV}_{2}$ were closely correlated $\left(r^{2}=0.79\right)$, with mean bias of $-11 \pm 80 \mathrm{ml}$ and percentage error of $14 \%$ (Figure 4). $E{ }^{2} W_{1}$ and $E_{2 L W}$ ranged from 507 to $2,379 \mathrm{ml}$ and from 495 to 2,222 $\mathrm{ml}^{\text {. EVLW }}{ }_{1}$ and $\mathrm{EVLW}_{2}$ were closely correlated $\left(r^{2}=0.97\right)$, with mean bias of $-5 \pm 72 \mathrm{ml}$ and percentage error of $15 \%$ (Figure 5).

Changes in $\mathrm{CO}_{2}, \mathrm{GEDV}_{2}$, and $\mathrm{EVLW}_{2}$ were closely correlated with changes in $\mathrm{CO}_{1}, \mathrm{GEDV}_{1}$, and EVLW ${ }_{1}$, respectively (Figure 6).

The effects of each intervention are summarized in Table 2. Inotropic stimulation (DOBU) was achieved by administering an average $23 \mu \mathrm{g} / \mathrm{kg} /$ minute dose of dobutamine, hypovolemia (HYPO) by an average 1.21 controlled hemorrhage, and hypervolemia (HYPER) by the average infusion of $4.5 \mathrm{l}$ serum saline and $1.5 \mathrm{l}$ gelatin. Both $G E D V_{1}$ and $G E D V_{2}$ decreased significantly during bleeding and increased significantly after blood restitution and fluid loading (Table 2). EVLW ${ }_{1}$ and EVLW increased slightly but significantly during fluid overload and dramatically $(+110 \%)$ during ALI (Table 2$)$. At each stage, values measured with the new VolumeView ${ }^{\mathrm{m}}$ and with the current $\mathrm{PiCCO}^{\mathrm{TM}}$ method were comparable (Table 2).

\section{Discussion}

In animals, and over a wide range of values, the present study demonstrates that GEDV and EVLW derived from the new VolumeView ${ }^{\text {TM }}$ method and from the current $\mathrm{PiCCO}^{\mathrm{TM}}$ method are interchangeable.

Both methods derive CO from the TPTD curve using the Stewart-Hamilton principles and the same equation [4] so, not surprisingly, the agreement was extremely good with a percentage error of $7 \%$, far below the clinically acceptable threshold value of $30 \%$ proposed by Critchley and Critchley [13].

In contrast, GEDV was derived from two different equations. The $\mathrm{PiCCO}^{\mathrm{TM}}$ equation is based on time characteristics of the TPTD curve (mean transit time of the cold indicator and exponential downslope time) while the new VolumeView ${ }^{\text {TM }}$ equation additionally relies on the ascending and descending slopes of the dilution curve (Figure 1). The present results show that both methods are interchangeable to assess GEDV even when significant changes in cardiac preload are induced by bleeding and fluid loading. They also confirm that GEDV is not affected by dobutamine-induced changes in $\mathrm{CO}$, and hence that there is no mathematical
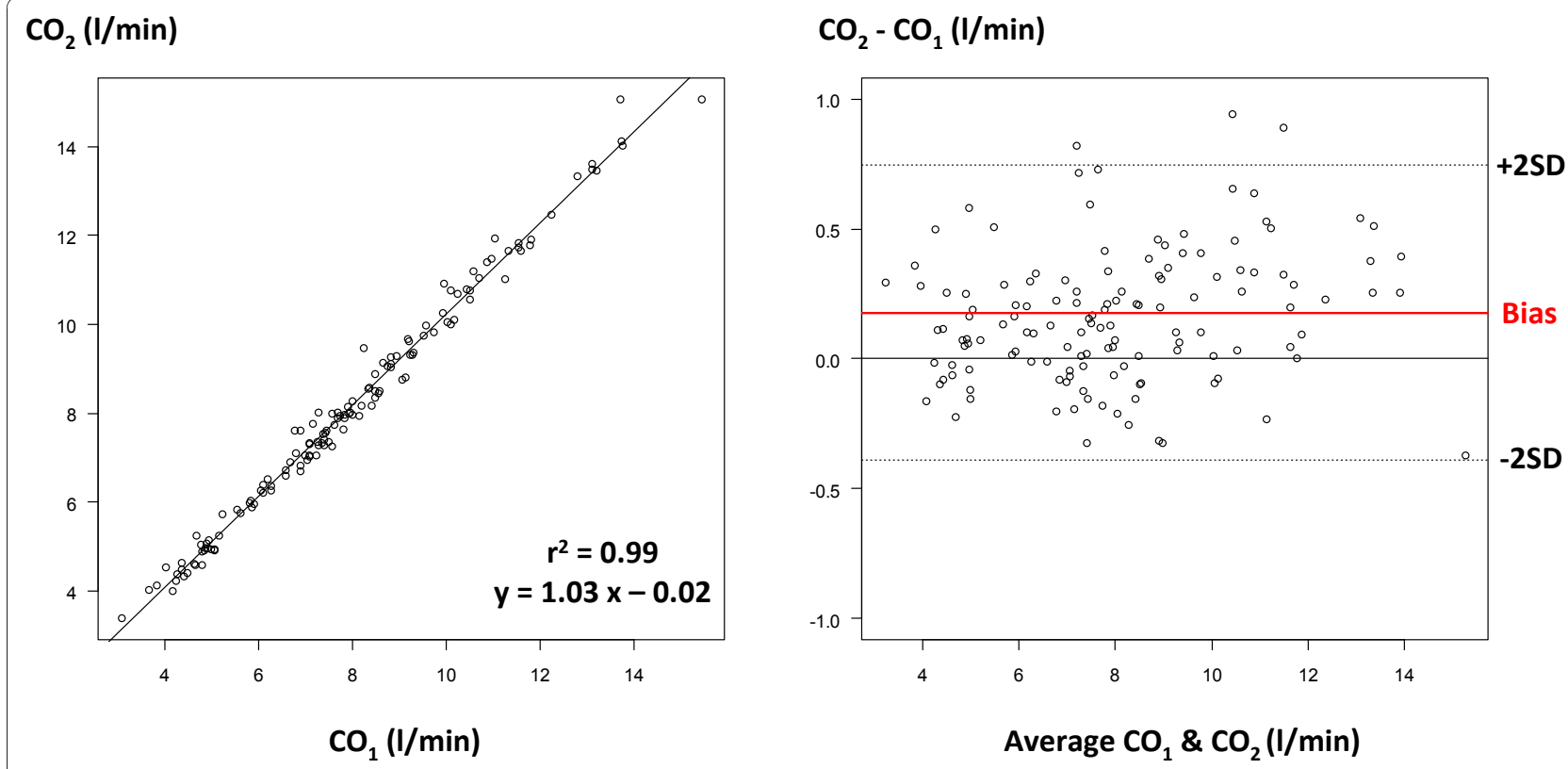

Figure 3 Cardiac output comparison. Left: correlation between cardiac output (CO) measured by the PiCCO ${ }^{\mathrm{TM}}$ system $\left(\mathrm{CO}_{1}\right)$ and the VolumeView ${ }^{\mathrm{TM}}$ system $\left(\mathrm{CO}_{2}\right)$. Right: Bland-Altman representation depicting the agreement between both methods. SD, standard deviation. 


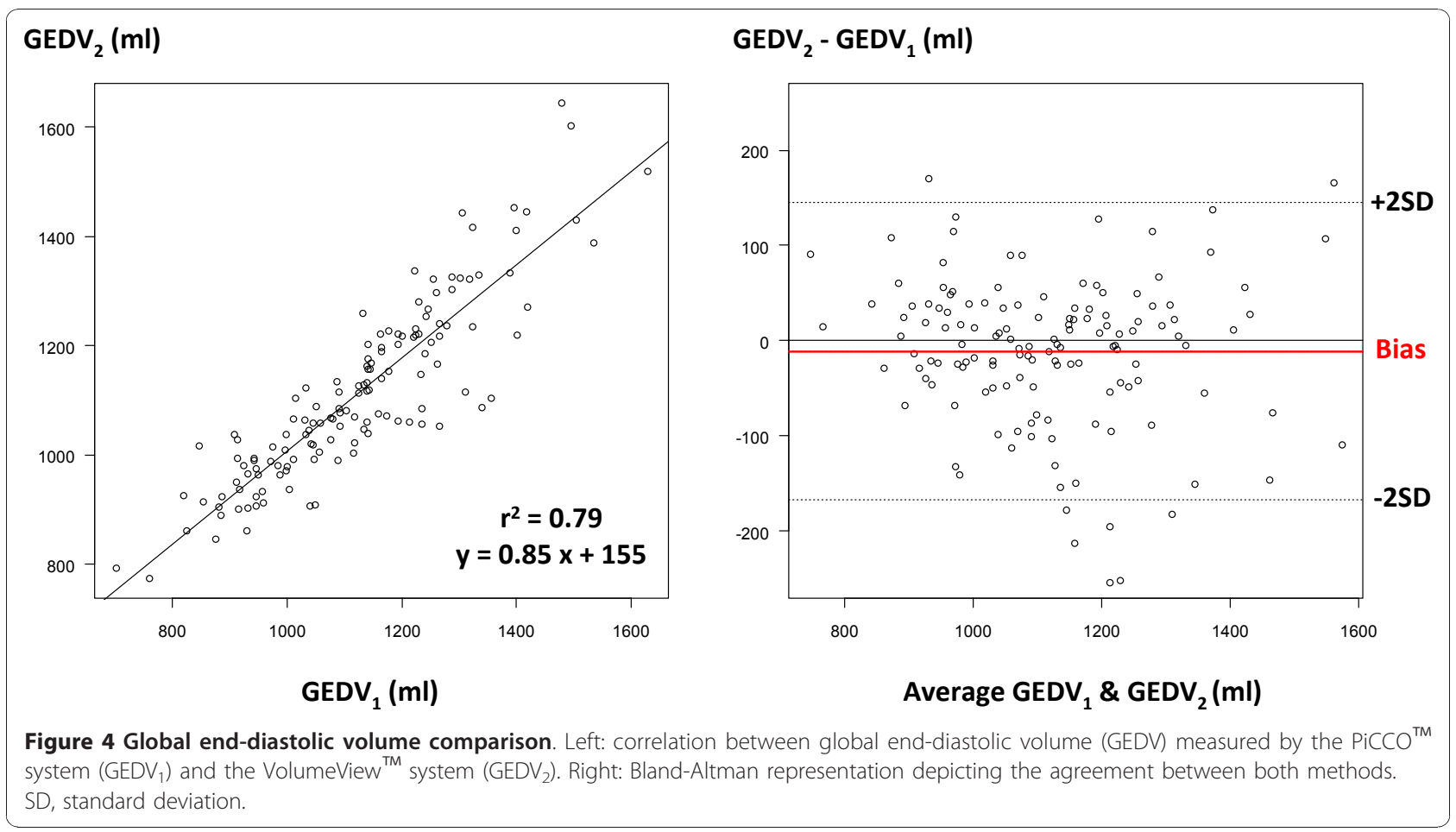

coupling between both parameters [3,5]. The GEDV has been shown to be a reliable indicator of cardiac preload [5], varying in the same direction as echocardiographic preload indices [6]. A goal-directed strategy based on the optimization of GEDV has been shown to be useful to improve the postoperative outcome of cardiac surgical patients [15].

Both methods were also interchangeable for the assessment of EVLW; not only during slight modifications induced by fluid overload, but also during
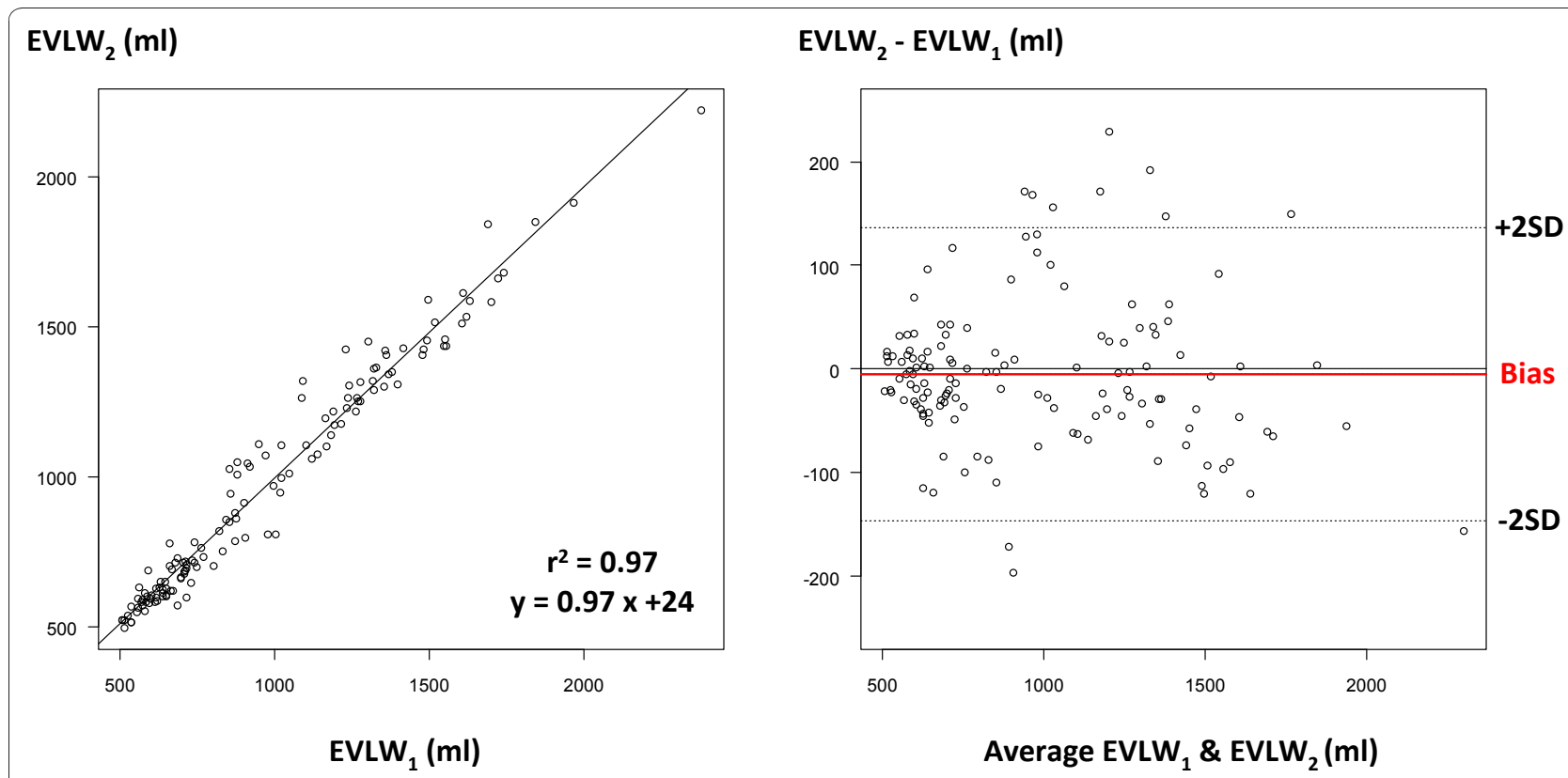

Figure 5 Extravascular lung water comparison. Left: correlation between extravascular lung water (EVLW) measured by the PiCCO ${ }^{\mathrm{TM}}$ system $\left(E V L W_{1}\right)$ and the VolumeView ${ }^{\mathrm{TM}}$ system $\left(E V L W_{2}\right)$. Right: Bland-Altman representation depicting the agreement between both methods. SD, standard deviation. 


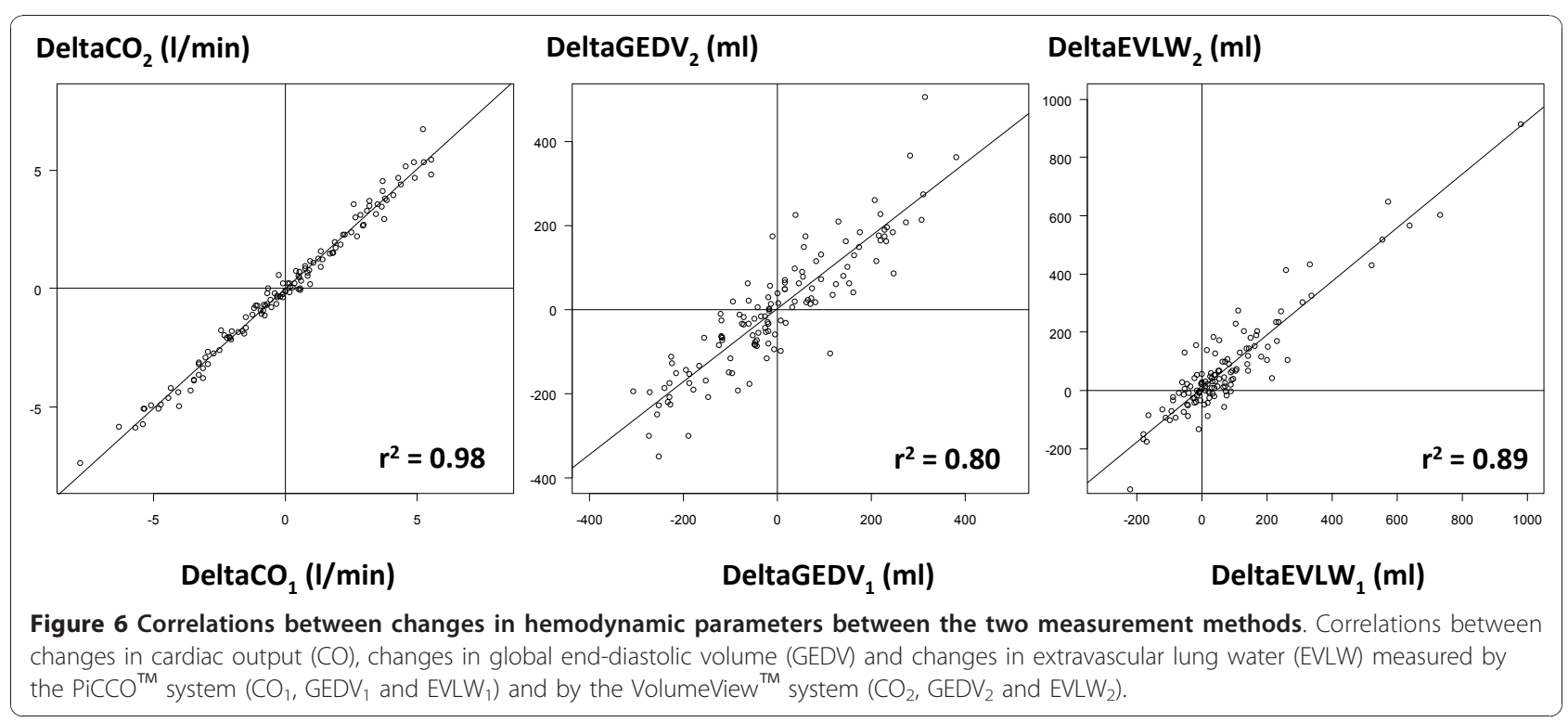

dramatic increases related to capillary leak as those observed during the ALI phase (Table 2). Assessing EVLW may be useful for clinicians treating patients with ALI or left ventricular failure [16]. EVLW has been shown to be more sensitive and specific than chest Xray and ALI criteria to diagnose pulmonary edema $[17,18]$. EVLW is also a prognostic parameter since it has repeatedly been shown to be correlated with mortality in patients with ALI as well as in the general intensive care unit population [19-22]. Moreover, it has been suggested in critically ill patients that goal-directed strategies based on the measurement of EVLW may be associated with a decrease in the duration of mechanical ventilation and length of hospital stay $[15,23,24]$.
Surprisingly, EVLW ${ }_{1}$ increased slightly but significantly during dobutamine infusion and decreased slightly but significantly during bleeding, while $\mathrm{EVLW}_{2}$ did not change (Table 2). From a pathophysiological point of view, no change in lung water is expected during inotropic stimulation or hypovolemia, particularly over such a short period of time [25]. Since our study was not designed to compare the $\mathrm{PiCCO}^{\mathrm{TM}}$ method and the VolumeView ${ }^{\text {TM }}$ method with a third reference method (such as gravimetry), however, we cannot draw any definitive conclusions regarding the superiority of one method over the other.

Our study also confirms the very good reproducibility of TPTD measurements. These findings are in line with

Table 2 Transpulmonary thermodilution parameters over the study period

\begin{tabular}{|c|c|c|c|c|c|c|c|}
\hline & BASE1 & DOBU & BASE2 & HYPO & BASE3 & HYPER & ALI \\
\hline $\begin{array}{l}\mathrm{CO}_{1} \\
(\mathrm{l} / \mathrm{min})\end{array}$ & $\begin{array}{l}7.5 \pm 0.9,7.6 \\
(6.9 \text { to } 8.2)\end{array}$ & $\begin{array}{l}10.8 \pm 1.4^{*}, 10.9 \\
(10.0 \text { to } 11.5)\end{array}$ & $\begin{array}{l}7.5 \pm 0.7,7.4 \\
(7.2 \text { to } 7.8)\end{array}$ & $\begin{array}{l}4.7 \pm 0.3^{*}, 4.9 \\
(4.5 \text { to } 4.9)\end{array}$ & $\begin{array}{l}7.9 \pm 1.2,7.7 \\
(7.2 \text { to } 8.6)\end{array}$ & $\begin{array}{l}11.7 \pm 2.1^{*}, 11.8 \\
(10.1 \text { to } 13.1)\end{array}$ & $\begin{array}{l}6.7 \pm 3.3^{*}, 5.2 \\
(4.5 \text { to } 8.7)\end{array}$ \\
\hline $\begin{array}{l}\mathrm{CO}_{2} \\
(\mathrm{l} / \mathrm{min})\end{array}$ & $\begin{array}{l}7.6 \pm 0.8,7.9 \\
(7.3 \text { to } 8.1)\end{array}$ & $\begin{array}{l}11.0 \pm 1.6^{*}, 11.0 \\
(10.1 \text { to } 11.7)\end{array}$ & $\begin{array}{l}7.6 \pm 0.8,7.3 \\
(7.1 \text { to } 8.1)\end{array}$ & $\begin{array}{l}4.8 \pm 0.2^{*}, 4.9 \\
(4.6 \text { to } 4.9)\end{array}$ & $\begin{array}{l}8.0 \pm 1.2,8.0 \\
(7.3 \text { to } 8.7)\end{array}$ & $\begin{array}{l}12.0 \pm 2.1^{*}, 11.8 \\
(10.5 \text { to } 13.5)\end{array}$ & $\begin{array}{l}6.9 \pm 3.4^{*}, 5.7 \\
(4.6 \text { to } 9.0)\end{array}$ \\
\hline $\begin{array}{l}\text { GEDV }_{1} \\
(\mathrm{ml})\end{array}$ & $\begin{array}{l}1,077 \pm 149,1,116 \\
(953 \text { to } 1,171)\end{array}$ & $\begin{array}{l}1,059 \pm 134 \\
1,001(958 \text { to } \\
1,167)\end{array}$ & $\begin{array}{l}1,110 \pm 147,1,139 \\
(990 \text { to } 1,230)\end{array}$ & $\begin{array}{l}925 \pm 84^{*}, 943 \\
\text { (885 to 977) }\end{array}$ & $\begin{array}{l}1,173 \pm 120,1,164 \\
(1,102 \text { to } 1,240)\end{array}$ & $\begin{array}{l}1,326 \pm 140^{*}, 1,288 \\
(1,245 \text { to } 1,440)\end{array}$ & $\begin{array}{l}1,070 \pm 191^{*}, 1,144 \\
\text { (929 to } 1,170)\end{array}$ \\
\hline $\begin{array}{l}\text { GEDV }_{2} \\
(\mathrm{ml})\end{array}$ & $\begin{array}{l}1,052 \pm 94,1,040 \\
(1,009 \text { to } 1,076)\end{array}$ & $\begin{array}{l}1,023 \pm 102 \\
1,038(942 \text { to } \\
1,056)\end{array}$ & $\begin{array}{l}1,093 \pm 124,1,117 \\
(1,000 \text { to } 1,177)\end{array}$ & $\begin{array}{l}931 \pm 66^{*}, 937 \\
\text { (911 to 978) }\end{array}$ & $\begin{array}{l}1,153 \pm 100,1,157 \\
(1089 \text { to } 1,214)\end{array}$ & $\begin{array}{l}1,299 \pm 162 *, 1,322 \\
(1,218 \text { to } 1,363)\end{array}$ & $\begin{array}{l}1,089 \pm 174^{*}, 1,118 \\
\text { (976 to } 1,194)\end{array}$ \\
\hline $\begin{array}{l}\mathrm{EVLW}_{1} \\
(\mathrm{ml})\end{array}$ & $\begin{array}{l}622 \pm 86,627 \\
(558 \text { to } 684)\end{array}$ & $\begin{array}{l}691 \pm 112,650 \\
(631 \text { to } 723)^{* *}\end{array}$ & $\begin{array}{l}653 \pm 106,639 \\
(577 \text { to } 692)\end{array}$ & $\begin{array}{l}609 \pm 72^{*}, 597 \\
(549 \text { to } 675)\end{array}$ & $\begin{array}{l}644 \pm 82,638 \\
(563 \text { to } 710)\end{array}$ & $\begin{array}{l}754 \pm 117,804 \\
(654 \text { to } 858)^{* *}\end{array}$ & $\begin{array}{l}1,587 \pm 380,1,609 \\
(1,305 \text { to } 1,711)^{* *}\end{array}$ \\
\hline $\begin{array}{l}\mathrm{EVLW}_{2} \\
(\mathrm{ml})\end{array}$ & $\begin{array}{l}621 \pm 82,613 \\
(552 \text { to } 683)\end{array}$ & $\begin{array}{l}642 \pm 68,628 \\
(596 \text { to } 666)\end{array}$ & $\begin{array}{l}635 \pm 85,619 \\
(592 \text { to } 678)\end{array}$ & $\begin{array}{l}624 \pm 68,626 \\
(580 \text { to } 679)\end{array}$ & $\begin{array}{l}624 \pm 80,587 \\
(567 \text { to } 710)\end{array}$ & $\begin{array}{l}749 \pm 128^{*}, 750 \\
(654 \text { to } 823)\end{array}$ & $\begin{array}{l}1,571 \pm 335^{*}, 1,580 \\
(1,374 \text { to } 1,752)\end{array}$ \\
\hline
\end{tabular}

Results are expressed as the mean \pm standard deviation, median (interquartile range). CO, cardiac output; GEDV, global end-diastolic volume; EVLW, extravascular lung water; subscript 1, current method (PiCCO ${ }^{\mathrm{TM}}$; Pulsion); subscript 2, new method (VolumeView ${ }^{\mathrm{TM}}$; Edwards); BASE, baseline; DOBU, dobutamine infusion; HYPO, hypovolemia induced by bleeding; HYPER, hypervolemia induced by volume loading; ALI, acute lung injury induced by oleic acid. ${ }^{*} P<0.01$ (DOBU vs. BASE1 or HYPO vs. BASE2 or HYPER vs. BASE3 or ALI vs. HYPER); normal distribution, paired $t$ test. ${ }^{* *} P<0.01$ (DOBU vs. BASE1 or HYPER vs. BASE3 or ALI vs. HYPER); abnormal distribution, nonparametric paired Wilcoxon signed-rank test. At each stage, values measured with the new VolumeView ${ }^{\text {TM }}$ and with the current $\mathrm{PiCCO}^{\mathrm{TM}}$ method were comparable. 
previous studies $[5,26]$ reporting reproducibility of $\mathrm{CO}$, GEDV and EVLW of 4 to $7 \%, 5$ to $8 \%$ and $11 \%$, respectively.

\section{Study limitations}

The gravimetric method in animals and the double indicator (cold green dye) dilution method in humans are considered gold standard methods to quantify EVLW $[9,10]$. The goal of the present study was to compare the new VolumeView ${ }^{\mathrm{rm}}$ system with the TPTD system currently in clinical use - this is why the $\mathrm{PiCCO}^{\mathrm{TM}}$ system has been selected as the reference method in our study. A clinical validation is necessary to investigate whether the new VolumeView ${ }^{\mathrm{TM}}$ system is also comparable with the $\mathrm{PiCCO}^{\mathrm{Tm}}$ system in critically ill patients. The new VolumeView ${ }^{\mathrm{Tm}}$ algorithm was originally developed to decrease the sensitivity of TPTD to recirculation and thermal baseline drifts. The present study was not designed to investigate this potential advantage over the existing TPTD technology, but instead to ensure that the new VolumeView ${ }^{\mathrm{TM}}$ system and the $\mathrm{PiCCO}^{\mathrm{TM}}$ system are interchangeable in clinical-like conditions where $\mathrm{CO}$, blood volume and lung water vary significantly. Further studies are therefore required to compare both systems in situations where technical (thermal baseline drift) or other clinical challenges (for example, valvular regurgitation-induced recirculation) are encountered.

\section{Conclusions}

In animals, and over a very wide range of values, the new TPTD VolumeView ${ }^{\text {TM }}$ system is comparable with the current $\mathrm{PiCCO}^{\mathrm{TM}}$ system to assess CO, GEDV and EVLW during inotropic stimulation, acute hemorrhage, fluid overload and severe acute lung injury.

\section{Key messages}

- TPTD is increasingly used for hemodynamic evaluations in critically ill patients.

- The TPTD method currently in clinical use and implemented in the $\mathrm{PiCCO}^{\mathrm{TM}}$ system (Pulsion Medical Systems) is based on mathematical models described in the $1950 \mathrm{~s}$

- A new and original method has recently been developed to derive GEDV and EVLW from a TPTD curve (VolumeView ${ }^{\text {тм}}$; Edwards Lifesciences).

- In animals, and over a very wide range of values, the new transpulmonary thermodilution VolumeView ${ }^{\mathrm{TM}}$ system is comparable with the current $\mathrm{PiCCO}^{\mathrm{TM}}$ system to assess CO, GEDV and EVLW during inotropic stimulation, acute hemorrhage, fluid overload and severe acute lung injury.

\begin{abstract}
Abbreviations
ALI: acute lung injury induced by oleic acid; $\mathrm{CO}$ : cardiac output; $\mathrm{CO}_{1}$ : cardiac output measured by $\mathrm{PiCCO}_{2}{ }^{\mathrm{TM}} ; \mathrm{CO}_{2}$ : cardiac output measured by EV1000; DOBU: dobutamine infusion; GEDV: global end-diastolic volume; GEDV global end-diastolic volume measured by $\mathrm{PiCCO}_{2}{ }^{\mathrm{TM}} ; \mathrm{GEDV}_{2}$ : global enddiastolic volume measured by EV1000; EVLW: extravascular lung water; $\mathrm{EVLW}_{1}$ : extravascular lung water measured by $\mathrm{PiCCO}_{2}{ }^{\mathrm{TM}} ; \mathrm{EVLW}_{2}$ : extravascular lung water measured by EV1000; HYPO: hypovolemia induced by bleeding; HYPER: hypervolemia induced by volume loading; MAP: mean arterial pressure; SD: standard deviation; TPTD: transpulmonary thermodilution.
\end{abstract}

\section{Acknowledgements}

The present study was funded by Edwards Lifesciences. The study was designed and conducted, and the results analyzed, under the supervision of $\mathrm{KB}$, with the support of Kate Willibyro (Edwards, Irvine, CA, USA) for data collection, Pascal Candolfi (Edwards, Nyon, Switzerland) for statistics, and Dr Michard (Edwards, Nyon, Switzerland) for design and writing. KB, RG and NS had full control of the database, which was locked before analysis, were responsible for interpretation of the results, and made the final decision to submit the manuscript for publication.

\section{Author details}

${ }^{1}$ Department of APSI, Geneva University Hospitals, 4 rue Gabrielle-PerretGentil, Genève 14-1211, Switzerland. 'Department of Critical Care, Edwards Lifesciences, 70 route de l'Etraz, Nyon 1260, Switzerland.

\section{Authors' contributions}

KB and FM designed the study and wrote the article. KB was responsible for data collection and data analysis, with the help of RG and NS. All authors reviewed and approved the final manuscript.

\section{Competing interests}

$\mathrm{KB}$ received consultant fees from Edwards LifeSciences. FM is a director at Edwards Lifesciences and is coinventor on transpulmonary thermodilution patents (US2005267378, US2007282213, WO2009049872). RG and NS have no potential conflicts of interest to declare.

Received: 26 June 2010 Revised: 8 October 2010

Accepted: 23 November 2010 Published: 23 November 2010

\section{References}

1. Michard F, Perel A: Management of circulatory and respiratory failure using less invasive hemodynamic monitoring. In Yearbook of Intensive Care and Emergency Medicine. Edited by: Vincent JL. Berlin: Springer; 2003:508-520.

2. Isakow W, Schuster DP: Extravascular lung water measurements and hemodynamic monitoring in the critically ill: bedside alternatives to the pulmonary artery catheter. Am J Physiol Lung Cell Mol Physiol 2006, 291: L1118-L1131.

3. Benington $S$, Ferris $P$, Nirmalan M: Emerging trends in minimally invasive haemodynamic monitoring and optimization of fluid therapy. Eur $J$ Anaesthesiol 2009, 26:893-905.

4. Reuter DA, Huang C, Edrich T, Shernan SK, Eltzschig HK: Cardiac output monitoring using indicator-dilution techniques: basics, limits, and perspectives. Anesth Analg 2010, 110:799-811.

5. Michard F, Alaya S, Zarka V, Bahloul M, Richard C, Teboul JL: Global enddiastolic volume as an indicator of cardiac preload in patients with septic shock. Chest 2003, 124:1900-1908.

6. Hofer CK, Furrer L, Matter-Ensner S, Maloigne M, Klaghofer R, Genoni M, Zollinger A: Volumetric preload measurement by thermodilution: a comparison with transoesophageal echocardiography. Br J Anaesth 2005, 94:748-755.

7. Sakka SG, Rühl CC, Pfeiffer UJ, Beale R, McLuckie A, Reinhart K, MeierHellmann A: Assessment of cardiac preload and extravascular lung water by single transpulmonary thermodilution. Intensive Care Med 2000, 26:180-187. 
8. Michard F, Schachtrupp A, Toens C: Factors influencing the estimation of extravascular lung water by transpulmonary thermodilution in critically ill patients. Crit Care Med 2005, 33:1243-1247.

9. Michard F: Bedside assessment of extravascular lung water by dilution methods: temptations and pitfalls. Crit Care Med 2007, 35:1186-1192.

10. Brown LM, Liu KD, Matthay MA: Measurement of extravascular lung water using the single indicator method in patients: research and potential clinical value. Am J Physiol Lung Cell Mol Physiol 2009, 297:L547-L558.

11. Newman EV, Merrell M, Genecin A, Monge C, Milnor WR, McKeever WP: The dye dilution method for describing the central circulation. An analysis of factors shaping the time-concentration curves. Circulation 1951, 4:735-746.

12. Meier $\mathrm{P}$, Zierler $\mathrm{KL}:$ On the theory of the indicator-dilution method for measurement of blood flow and volume. J Appl Physiol 1954, 6:731-744.

13. Critchley LA, Critchley JA: A meta-analysis of studies using bias and precision statistics to compare cardiac output measurement techniques. J Clin Monit Comput 1999, 15:85-91.

14. Bland JM, Altman DG: Agreement between methods of measurement with multiple observations per individual. J Biopharm Stat 2007, 17:571-582.

15. Goepfert MSG, Reuter DA, Akyol D, Lamm P, Kilger E, Goetz A: Goaldirected fluid management reduces vasopressor and catecholamine use in cardiac surgery patients. Intensive Care Med 2007, 33:96-103.

16. Michard F, Phillips C: Measuring extravascular lung water (and derived parameters) in patients with acute respiratory distress syndrome: what's right, what's wrong, and what's ahead? Crit Care Med 2009, 37:2118-2119.

17. Michard F, Zarka V, Alaya S: Better characterization of acute lung injury/ ARDS using lung water. Chest 2004, 125:1166-1167.

18. Martin GS, Eaton S, Mealer M, Moss M: Extravascular lung water in patients with severe sepsis: a prospective cohort study. Crit Care 2005, 9: R74-R82.

19. Berkowitz DM, Danai PA, Eaton S, Moss M, Martin GS: Accurate characterization of extravascular lung water in acute respiratory distress syndrome. Crit Care Med 2008, 36:1803-1809.

20. Sakka SG, Klein M, Reinhart K, Meier-Hellmann A: Prognostic value of extravascular lung water in critically ill patients. Chest 2002 122:2080-2086.

21. Kuzkov W, Kirov MY, Sovershaev MA, Kuklin VN, Suborov EV, Waerhaug K, Bjertnaes $L$ : Extravascular lung water determined with single transpulmonary thermodilution correlates with the severity of sepsisinduced acute lung injury. Crit Care Med 2006, 34:1647-1653.

22. Phillips CR, Chesnutt MS, Smith SM: Extravascular lung water in sepsisassociated acute respiratory distress syndrome: indexing with predicted body weight improves correlation with severity of illness and survival. Crit Care Med 2008, 36:69-73.

23. Mitchell JP, Schuller D, Calandrino FS, Schuster DP: Improved outcome based on fluid management in critically ill patients requiring pulmonary artery catheterization. Am Rev Respir Dis 1992, 145:990-998.

24. Eisenberg PR, Hansbrough JR, Anderson D, Schuster DP: A prospective study of lung water measurements during patient management in an intensive care unit. Am Rev Respir Dis 1987, 136:662-668.

25. Nirmalan M, Willard TM, Edwards DJ, Little RA, Dark PM: Estimation of errors in determining intrathoracic blood volume using the single transpulmonary thermal dilution technique in hypovolemic shock. Anesthesiology 2005, 103:805-812.

26. Gödje O, Peyerl M, Seebauer T, Dewald O, Reichart B: Reproducibility of double-indicator dilution measurements of intrathoracic blood compartments, extravascular lung water, and liver function. Chest 1998, 113:1070-1077.

doi:10.1186/cc9332

Cite this article as: Bendjelid et al.: Validation of a new transpulmonary thermodilution system to assess global end-diastolic volume and extravascular lung water. Critical Care 2010 14:R209.

\section{Submit your next manuscript to BioMed Central and take full advantage of:}

- Convenient online submission

- Thorough peer review

- No space constraints or color figure charges

- Immediate publication on acceptance

- Inclusion in PubMed, CAS, Scopus and Google Scholar

- Research which is freely available for redistribution 